University of Nebraska - Lincoln

DigitalCommons@University of Nebraska - Lincoln

Industrial and Management Systems

Industrial and Management Systems

Engineering Faculty Publications

Engineering

2002

\title{
Assessment of Slip Severity Among Different Age Groups
}

Thurmon E. Lockhart

Virginia Polytechnic Institute and State University

Jeffrey C. Woldstad

Oregon State University, Jeffrey.Woldstad@sdsmt.edu

James L. Smith

Texas Tech University

Follow this and additional works at: https://digitalcommons.unl.edu/imsefacpub

Part of the Operations Research, Systems Engineering and Industrial Engineering Commons

Lockhart, Thurmon E.; Woldstad, Jeffrey C.; and Smith, James L., "Assessment of Slip Severity Among Different Age Groups" (2002). Industrial and Management Systems Engineering Faculty Publications. 13. https://digitalcommons.unl.edu/imsefacpub/13

This Article is brought to you for free and open access by the Industrial and Management Systems Engineering at DigitalCommons@University of Nebraska - Lincoln. It has been accepted for inclusion in Industrial and Management Systems Engineering Faculty Publications by an authorized administrator of DigitalCommons@University of Nebraska - Lincoln. 


\title{
Assessment of Slip Severity Among Different Age Groups
}

Thurmon E. Lockhart, Grado Department of Industrial and Systems Engineering (0118), 250 Durham Hall, Virginia Polytechnic Institute and State University, Blacksburg, VA

Jeffrey C. Woldstad, Industrial and Manufacturing Engineering, Oregon State University, Corvallis, OR

James L. Smith, Department of Industrial Engineering, Texas Tech University, Lubbock, TX

\begin{abstract}
A laboratory study utilizing new techniques for assessing slip severity was conducted to investigate the process of inadvertent slips and falls among different age groups. Fortytwo subjects from three age groups (young adults, middle-aged, and the elderly) walked on a rectangular track at a self-determined pace. Without the subjects' awareness, a slippery floor surface was placed on the track over a force-measuring platform. The results indicated that elderly adults' friction demand (RCOF) was not significantly different from the young and middle-aged adults. The older adults, however, fell more often than the other age groups. Fall recovery threshold (FRT) measures indicated that younger adults were able to recover from a slip (thus preventing a fall) with higher sliding speeds and longer slip distances than older adults. Additionally, older adults' adjusted friction utilization (AFU) on the slippery floor surface was not adjusted within the dynamic friction requirements, resulting in more falls. Based on the age-related differences observed, it appears that fall-related accidents among older adults are due more to factors influencing compensation of a slip rather than gait characteristics influencing slip initiation.
\end{abstract}

Keywords: slips and falls, slip severity, fall recovery, gait biomechanics, aging, friction demand, slip distances, heel velocity, coefficient of friction

\section{Introduction}

Reducing slip and fall accidents has been a goal of many researchers since the 1920s. Four primary approaches have been traditionally used to understand slip and fall accidents: epidemiology, biomechanics, tribology, and psychophysics. In spite of improvements in tribometric techniques to assess shoe/floor interactions, increased knowledge of the biomechanical responses to walking on slippery floor surfaces, and numerous studies exploring postural control, fall accidents continue to represent a 
significant burden to society in terms of both human suffering and economic losses. Older adults are particularly at risk. Falls are the leading cause of death resulting from injury among those over 75 years old and the second highest cause of accidental death for 45-75 year olds [1]. Furthermore, with longer life expectancy and increased proportion of the older adults in the overall population, society in the aggregate is likely to experience a greater risk for slip and fall accidents, which may pose additional burden on the health care system [2].

A review of the literature indicates that multiple mechanisms are involved in slip and fall accidents. In general, fall accidents on level walking surfaces are believed to be the result of a loss of traction between the shoe and the walkway surface $[3,4]$. The term "slip" has often been used to describe this loss of traction, both when the slip results in a fall and when it does not [5]. Recently, slip classifications have been used as a measure of floor surface slipperiness [6]. The term slipperiness has been defined as "underfoot conditions which may interfere with human [ambulation], causing a foot slide that may result in injury or harmful loading of body tissues due to a sudden release of energy" [7]. In addition to interest in slips and microslips as potential indicators of slipperiness, gait parameters (such as required coefficient of friction [RCOF]) at the point of initial foot contact are of interest for tribological studies $[8,9]$.

Slip behavior has been investigated by many researchers $[6,8,10]$. hi terms of the biomechanical approach to the prevention of slips and falls, much attention has been focused on studying of the slip behavior of young individuals. Actual slip experiments were conducted on subjects wearing test shoes, walking from non-slippery surfaces onto slippery surfaces, utilizing a fall arresting rig to prevent injuries, $m$ the majority of experiments, slips occurred in a forward direction having started shortly after the heel contacted a contaminated surface, hi some cases the shoe only slipped a few centimeters and then stopped, so that the subjects were able to regain balance and continue walking. In other cases, the foot continued slipping, and the subjects were unable to recover balance. The severity of a slip (whether or not the slip resulted in a fall) therefore, appears to be dependent on the distance that subject's foot slipped (for example, any slip distance more than 10 to $15 \mathrm{~cm}$ resulted in loss of balance [10]). Perkins [8] noted that this effect is probably related to the acceleration of the foot as it slips forward. He further noted that if the foot travels faster than the body, the body can never catch up, but if the body is able to overtake the slipping foot, the slip may be able to be arrested.

Although the above concepts are sound and logical, currently there exist no universal definitions (or the robust technique) for assessing slip severity. In other words, there exist no unambiguous methodologies to assess severity of a slip such as slip distance, sliding speeds, and friction utilization during slipping. Strandberg and Lanshammar [II], for example, identified slips by examining the coordinates of the heels. They defined the slip-start point as occurring at the first minimum of the heel's forward velocity; but, they did not discuss how to determine slip-stop point. Perkins [8] did not specify how to determine the slip-start or the slip-stop points. Rather, he presented stroboscopic multi- image photographs of heel slip.

The purpose of this study was to develop a method to assess slip severity among different age groups. This was accomplished by closely examining the slip behaviors of individuals from three different age groups (young, middle-aged, and the elderly), and defining the repeatable gait patterns during the related events of slips and falls. 
We have also investigated, utilizing new models for assessing slip severity, the process of initiation of and recovery from inadvertent slips and falls among different age groups, taking care so as not to confound our results with safety-harness artifacts. We hypothesize that slip severity (as measured by slip distances, sliding heel velocity, sliding heel acceleration, and adjusted friction utilization) will be greater among older individuals than their younger counterparts.

\section{Experimental Method}

\section{Subjects}

Fourteen young adults (7 male and 7 female, aged 18-29), 14 middle-aged adults (7 male and 7 female, aged 35-59), and 14 senior citizens (7 male and 7 female, over 65 years of age) participated in these experiments. (Age, height and weight information are presented in Table 1.) The young subjects were recruited from the general student population at Texas Tech University and older subjects were recruited from the local community. Prior to participating in the experiment, older subjects were examined by a physician to ensure that they were in generally good physical health. Subjects also received a peripheral neuropathy examination in the Neurology Department at St. Mary's Hospital in Lubbock, Texas. Subjects were excluded from the study based on these tests or upon the physician's professional judgment. Each participant completed an informed consent procedure approved by the Texas Tech Institutional Review Board. All participants were compensated for their time and effort.

\section{Apparatus}

Two commonly used floor materials were used in this experiment: outdoor carpet ("Beau Lieu" Olefin) and vinyl tile (Armstrong). The vinyl tile surface was covered with motor oil (10W40) to reduce the coefficient of friction (COF). The available dynamic COF (ADCOF) for each surface was measured using a standard $4.54 \mathrm{Kg}$ (10 lb.) horizontal pull slipmeter with a rubber sole material and found to be 1.80 for the outdoor carpet and 0.08 for the oily vinyl tile. ADCOF measurements were conducted at a constant velocity of $20 \mathrm{~cm} / \mathrm{sec}$. Averages of 10 measurements on each of the two floor surfaces were used to characterize the ADCOF values.

Walking trials were conducted on an instrumented rectangular track (Figure 1). Its wooden deck was approximately 6.7 meters $\times 6.7$ meters, permitting a straight walk-

Table 1. Subject information.

\begin{tabular}{|c|c|c|c|c|c|}
\hline \multirow[b]{2}{*}{ Age (years) } & \multicolumn{2}{|c|}{$\begin{array}{c}\text { Young } \\
\text { Mean (S.D.) }\end{array}$} & \multicolumn{2}{|c|}{$\begin{array}{c}\text { Middle } \\
\text { Mean (S.D.) }\end{array}$} & $\begin{array}{c}\text { Old } \\
\text { Mean (S.D.) }\end{array}$ \\
\hline & 26 & (2.1) & 46.9 & (13.6) & 75.5 \\
\hline Height (cm) & 169.7 & (6.1) & 173.5 & $(6.3)$ & 170.2 \\
\hline Weight (kg) & 68.7 & $(9.6)$ & 75.5 & (16.1) & $76.8 \quad(13.3)$ \\
\hline
\end{tabular}


ing path (subjects were instructed to walk straight after turning). The entire deck was covered with carpet. A remote controlled floor changer was used to change the test floor surfaces so as to provide unexpected slippery conditions.

The test surfaces (oily vinyl floor tiles) were mounted on a platform that was connected to the force plates (black box on the track, Figure 1). The floor-changing system allowed a subject to walk under experimental conditions without being aware of the floor-surface change. Subjects were also supplied with a Walkman ${ }^{\circledR}$ (listening to old comedy routines) during the walking experiment to conceal the sound of the floor changer's motor.

A fall arresting rig was used to protect subjects from falling during the experiment. The rig consists of a full-body parachute harness attached to a servo-driven overhead suspension arm. A feedback control system allowed the arm to sense the position of the subject and increase or reduce velocity to stay overhead. Additionally, the telescoping boom connected to the arm was programmed to move in and out to allow a straight walking path. The rig was designed to permit the subject to fall approximately $15 \mathrm{~cm}$ before arresting the fall and stopping the forward motion.

The ground reaction forces of the subjects walking over the test surfaces were measured using two Bertec force plates sampled at a rate of $600 \mathrm{~Hz}$. An Ariel Performance Analysis System and four Panasonic video recorders, sampling and recording at a rate of $60 \mathrm{~Hz}$, were used to collect the three-dimensional postural data as they walked over the test surface.

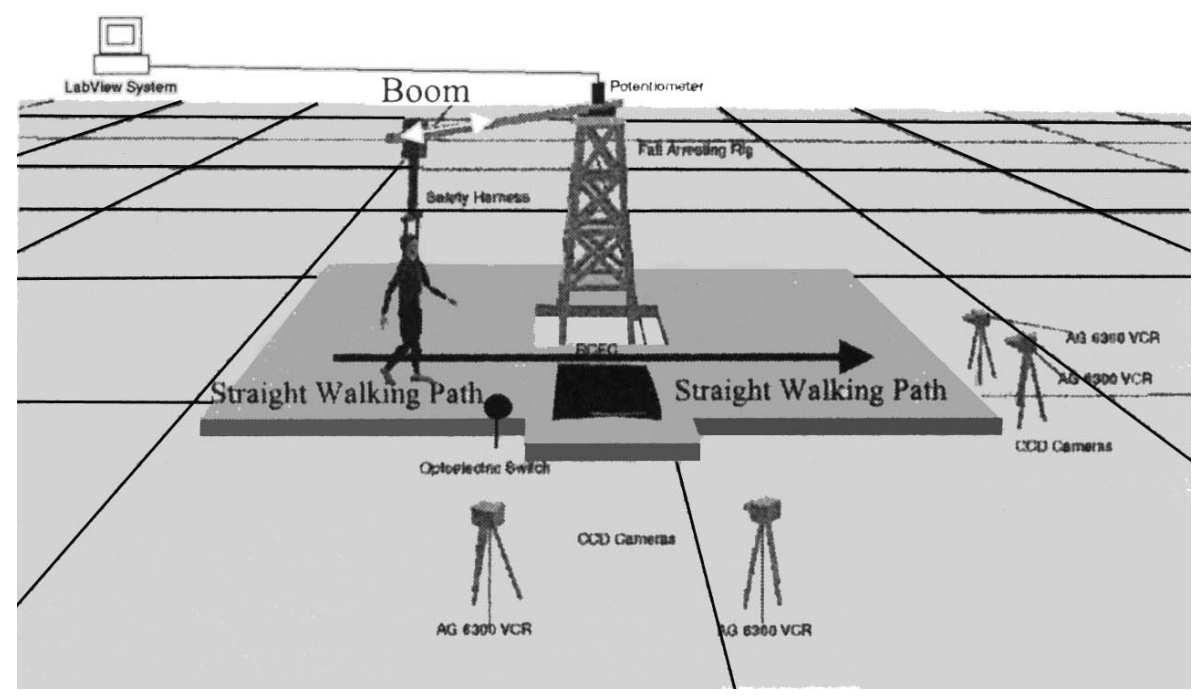

Figure 1. Experimental setup including fall arresting rig and harness, boom. cameras (4), optoelectric switch, and data collection system. Movement of the boom (arrow) side to side allowed straight walking path after turning. 


\section{Procedure}

The subjects were scheduled to participate in two testing sessions within one week's time. The subjects attended a familiarization session before the experiment. During the familiarization, the fall arresting system and walking conditions were introduced. Prior to the walking experiment, retro-reflectors were attached to anatomically significant body positions: 26 body markers defined a 14-segment whole body model [12]. Foot segments were analyzed for this study. The heel target was placed on the outer-edge of the shoe ( $2.4 \mathrm{~cm}$ from rear-edge and bottom of the shoe). The target representing the toe was placed $2.5 \mathrm{~cm}$ above the sole, on the outer-edge of the foot. During the experiment, the subjects walked across each floor condition for $10 \mathrm{~min}$. While walking, subjects were instructed to focus their eyes on a light emitting diode located approximately 2 meters above and 3 meters away from the testing area. A secondary task that required them to call out when the light was on and when it was off was used to ensure that they attended to the LED. During each of the 10 min sessions, two slippery conditions were randomly introduced by the system, and measurements of subject's posture and ground reaction forces were recorded (second trial was used only if first trial was not robusti.e., not stepping on the force plate). Location of the slippery surface was randomly distributed by the two floor changers. Standard shoes with rubber soles were supplied to all subjects to reduce COF variability between shoe sole and test-floor surfaces.

\section{Calculations of Dependent Measures}

Figure 2 illustrates typical slip parameters over time, starting at heel contact, which we defined as the instant when the vertical ground reaction force (GRF) exceeded ION. To synchronize kinetic and kinematic variables, an LED was coupled to the vertical force output of the force plates and when the force exceeded ION the LED was triggered.

Initially, as indicated by horizontal heel positions, the heel does not slip forward considerably (horizontal heel velocity decreases as the heel quickly decelerates during this time period). This is believed to be the result of the position of the whole body COM (closer to the rear foot) [12] during the heel contact phase of the gait cycle. Shortly after heel contact (approx. $60 \mathrm{~ms}$ ) (as the fore-foot comes down and the whole body COM shifts towards the sliding heel), the heel begins to slip forward considerably. Afterwards, the sliding heel reaches maximum velocity. During this slipping period, the heel accelerates reaching the maximum near the mid-point of the sliding heel velocity profile.

After reaching maximum sliding heel velocity, the sliding heel velocity decreases to the minimum, halting further slipping (not shown in Figure 2).

Slip Distance: Son [13], utilizing the three-dimensional coordinates of the heel reflector, identified the slip-start point at the instant at which the horizontal heel acceleration passed through zero (going from negative to positive, equivalent to the first minimum of the horizontal heel velocity after the heel contact). Son also defined the slip- stop point at the instant the first minimum of the horizontal heel velocity after the slip- start point (not shown in figure 2). Son's definitions are much clearer than the others $[8,10]$. Alteration of the vertical and horizontal force profiles beyond the point of maximum horizontal heel velocity due to interaction of the test subject with 
a)

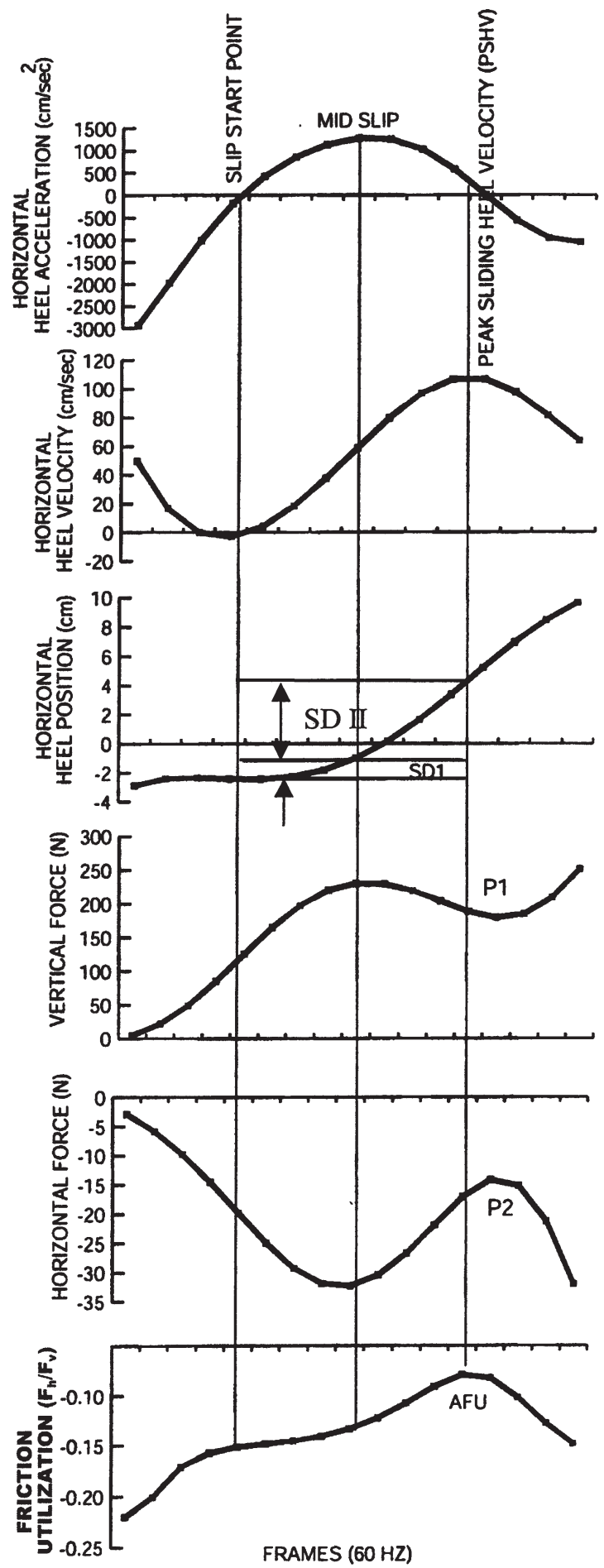

Figure 2. Composite view of the slip parameters. Each tick marker represents 1/60 second. 
the safety harness is an issue that must be considered. Figure 2 illustrates this concept. The vertical force profile (at P1) illustrates that there is a significant decrease in vertical force as the subject slips (after reaching peak heel sliding velocity). This decrease in vertical force may have resulted when the subject tried to compensate for a slip by utilizing the fall arresting harness or by the automatic support given to falling subjects by the harness. In the process, interactions with the harness can affect the horizontal force profile (P2). Thus, beyond the peak heel velocity point, because the fall arresting harness may affect the biomechanical parameters of slip severity (such as slip distance, slipping velocity etc), the use of any metrics that take into account events post-peak-heel-sliding would be problematic. Given that, we have defined two novel slip distances $\left(\mathrm{SD}_{\mathrm{I}}\right.$ and $\left.\mathrm{SD}_{\mathrm{II}}\right)$.

Initial Slip Distance $\left(\mathrm{SD}_{\mathrm{I}}\right)$ : the initial distance traveled by the foot after the heel- contact phase of the gait cycle was measured to provide information concerning the severity of slip initiation. The slip-start point $\left(X_{1}, Y_{1}\right)$ was defined in the same manner that Son defined the slip-start point. The slip-stop point for $\operatorname{SD}_{I}\left(X_{2}, Y_{2}\right)$, is defined differently. Our slip-stop point occurs at the instant that the peak horizontal heel acceleration occurs after the slip-start point (the mid-slip point on Figure $2 \mathrm{a}$ ). $\mathrm{SD}_{\mathrm{I}}$ is calculated using the heel coordinates between slip-start $\left(X_{1}, Y_{1}\right)$ and slip-stop $\left(X_{2}, Y_{2}\right)$ points using the Pythagorean distance formula. (See Figure 2c.)

$$
\mathrm{SD}_{\mathrm{I}}=\left[\left(\mathrm{X}_{2}-\mathrm{X}_{1}\right)^{2}+\left(\mathrm{Y}_{2}-\mathrm{Y}_{1}\right)^{2}\right]^{1 / 2}
$$

Slip Distance II $\left(\mathrm{SD}_{\mathrm{II}}\right)$ was developed to provide information concerning the slip behavior after the initiation of slips. The start-instant for the $\mathrm{SD}_{\mathrm{II}}$ is defined as slip-stop point for $\mathrm{SD}_{\mathrm{I}}$, i.e., mid-slip on Figure 2a. The end point of $\mathrm{SD}_{\mathrm{II}}$ is the instant where the first maximum of the horizontal heel velocity after slip-start point occurred (seen as the Peak Sliding Heel Velocity [PSHV] in Figures $2 \mathrm{a}$ and $2 \mathrm{~b}$ ). $\mathrm{SD}_{\mathrm{II}}$ was also calculated utilizing the Pythagorean distance formula (1).

Average Sliding Heel Velocity $\left(\bar{v}_{s}\right)$ : The average sliding heel velocity $\left(\bar{v}_{s}\right)$ of the heel after heel contact was calculated by averaging the instantaneous sliding heel velocity (ISHV) starting one frame before the slip-start point and ending one frame after the PSHV point (Figure 2a) and using the formula:

$$
\begin{array}{r}
\mathrm{ISHV}_{\mathrm{k}+1}=\left[\mathrm{X}_{(\mathrm{k}+\mathrm{i}+\mathrm{i})}-\mathrm{X}_{(\mathrm{k}+\mathrm{i}-1)}\right] / 2 \Delta \mathrm{t} \quad \begin{array}{r}
\text { where, } \mathrm{k}=\text { slip start point } \\
\text { and } \mathrm{i}=\text { slip frame number }
\end{array}
\end{array}
$$

thus,

$$
\bar{v}_{s}=\sum_{i=1}^{N} \mathrm{ISHV}_{\mathrm{k}+\mathrm{i}} / \mathrm{N} \quad \text { where, } \mathrm{N}=\text { total slip frames }
$$

Average Sliding Heel Acceleration $\left(H_{a c c}\right)$ : The average sliding heel acceleration of the heel after heel contact was calculated by averaging the instantaneous sliding heel acceleration between the slip-start and slip-stop points. 
Peak Adjusted Friction Utilization (AFU): AFU is the measured ratio $\left(\mathrm{F}_{\mathrm{h}} / \mathrm{F}_{\mathrm{v}}\right)$ of the horizontal foot force $\left(\mathrm{F}_{\mathrm{h}}\right)$ to the vertical foot force $\left(\mathrm{F}_{\mathrm{v}}\right)$ at the slip-stop point, and represents the ability to adjust dynamic frictional requirements during slipping [7]. The significance of this ratio is that it indicates when the gait compensation for a slip is most likely to occur. Figure 2 illustrates this concept. In Figure 2, as the horizontal heel velocity reaches its maximum, the magnitude of the horizontal force is decreasing (as is the vertical force), and the magnitude of the ratio of the horizontal to vertical force decreases. At that instant, if AFU is higher than the available dynamic coefficient of friction (ADCOF), the heel will continue to increase in velocity; however, on these data, (i.e., Figure 2), AFU is lower than the ADCOF, and the heel decelerates (the beginning of halting or controlling a slip.

Step Length (SL): The linear distance in the direction of progression between successive points of foot-to-floor contact of one foot and then the other foot was measured on both the carpet and the oily tile surfaces. The resultant step lengths were calculated from the difference between consecutive positions of the heels contacting the floor using the Pythagorean distance formula (1).

Heel Contact Velocity $\left(v_{h c}\right)$ : The instantaneous horizontal heel velocity $\left(v_{h c}\right)$ at heel contact was calculated on both the carpet and the oily-tile surfaces utilizing heel velocities in the plane of contact at foot displacements of $1 / 60$ second (the video-frame time, $\left.t_{\text {frame }}\right)$ before and after the heel-contact phase of the gait cycle.

Friction Demand (RCOF): The required coefficient of friction (RCOF) was obtained by dividing the horizontal ground reaction force by the vertical ground reaction force $\left(\mathrm{F}_{\mathrm{h}} / \mathrm{F}_{\mathrm{v}}\right)$ after heel contact (peak 3 as defined by Perkins [8]) on the carpeted floor surface to obtain the initial friction demand.

\section{Treatment of Data}

The converted coordinate data for each of the body markers and the ground reaction forces were digitally smoothed using a fourth-order, zero-lag, low-pass Butterworth filter. The dependent measures: the slip distances $\left(\mathrm{SD}_{\mathrm{I}}\right.$ and $\left.\mathrm{SD}_{\mathrm{II}}\right)$, average sliding heel velocity, average sliding heel acceleration, and adjusted friction utilization during slipping, were analyzed using separate one-way repeated-measures ANOVAs with age groups as the independent variable. (Significance was assumed when a 0.05). To test whether or not subjects had an awareness that the floor surfaces had been switched, step length (SL) and horizontal heel contact velocity $\left(v_{h c}\right)$ were each analyzed using a separate $2 \times 2$ (age group $\times$ floor surface) repeated-measures ANOVA. RCOF was analyzed using a one-way analysis of variance on the carpeted floor surface.

Table 2 summarizes slip parameters among three different age groups. 
Table 2. Summary of slip parameters among three different age groups

\begin{tabular}{llll}
\hline \multirow{2}{*}{ Variables } & $\begin{array}{l}\text { Young } \\
\text { Mean (S.D.) }\end{array}$ & $\begin{array}{l}\text { Middle } \\
\text { Mean (S.D.) }\end{array}$ & $\begin{array}{c}\text { Old } \\
\text { Mean (S.D.) }\end{array}$ \\
\hline Slip Distance I (cm) $\left(\mathrm{SD}_{\mathrm{I}}\right)$ & $1.08(1.49)$ & $2.30(1.48)$ & $2.17(1.37)$ \\
* Slip Distance II $(\mathrm{cm})\left(\mathrm{SD}_{\mathrm{II}}\right)$ & $4.25(3.24)$ & $6.25(3.27)$ & $7.67(3.48)$ \\
* Average Sliding Heel Velocity $(\mathrm{cm} / \mathrm{s})$ & $47.34(9.74)$ & $61.86(9.17)$ & $75.84(9.86)$ \\
* Average Sliding Heel Acc. $\left(\mathrm{cm} / \mathrm{s}^{2}\right)$ & $609.50(79.2)$ & $907.80(73.5)$ & $912.10(66.6)$ \\
* Peak Adjusted Friction Utilization & $0.074(0.01)$ & $0.10(0.01)$ & $0.12(0.01)$ \\
* Step Length $(\mathrm{cm})$ & $65.35(7.34)$ & $67.63(9.05)$ & $59.12(7.67)$ \\
Heel Contact Velocity $(\mathrm{cm} / \mathrm{s})$ & $31.03(14.5)$ & $32.11(13.5)$ & $42.31(17.9)$ \\
RCOF & $0.176(0.01)$ & $0.188(0.02)$ & $0.192(0.02)$ \\
\hline
\end{tabular}

* Statistically Significant $(p \leq 0.05)$.

\section{Results}

Slip Parameters

The results of a one-way ANOVA on $\mathrm{SD}_{\mathrm{I}}$ indicated no statistically significant differences between the age groups $\left(F_{(2,39)}=2.989, p \approx 0.06\right)$.

The results of a one-way ANOVA on $\mathrm{SD}_{\mathrm{II}}$ indicated significant differences with respect to age group $\left(F_{(2,39)}=3.69, p \approx 0.034\right)$. Tukey-Kramer post-hoc tests indicated that the older age group's $\mathrm{SD}_{\mathrm{II}}$ was significantly longer $(p \approx 0.0001)$ than both the young and middle-age groups, and that there were no significant differences between middle and older-age groups.

The results of a one-way ANOVA on average sliding heel velocity $\left(\bar{v}_{s}\right)$ indicated that there were significant differences in this parameter as a function of age group $\left(F_{(2,39)}=5.536, p \approx 0.007\right)$. Tukey-Kramer post-hoc tests indicated that the older age group's $\bar{v}_{s}$ was significantly faster $(p \approx 0.0001)$ than younger-age group. No statistically significant differences were found between the middle-age and older-age groups. (See Figure 3).

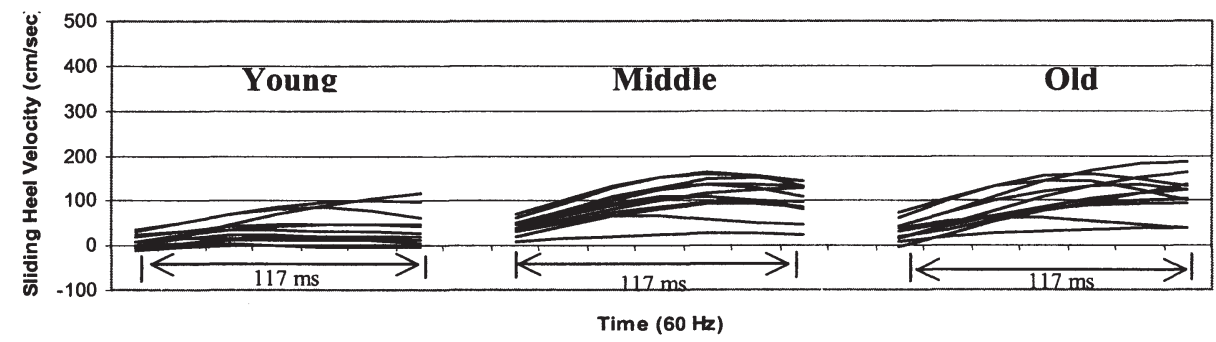

Figure 3. Composite patterns of sliding heel velocity profile of each individual starting from heel contact to $117 \mathrm{~ms}$ after heel contact on the oily vinyl floor surface among young, middle, and old subjects. 


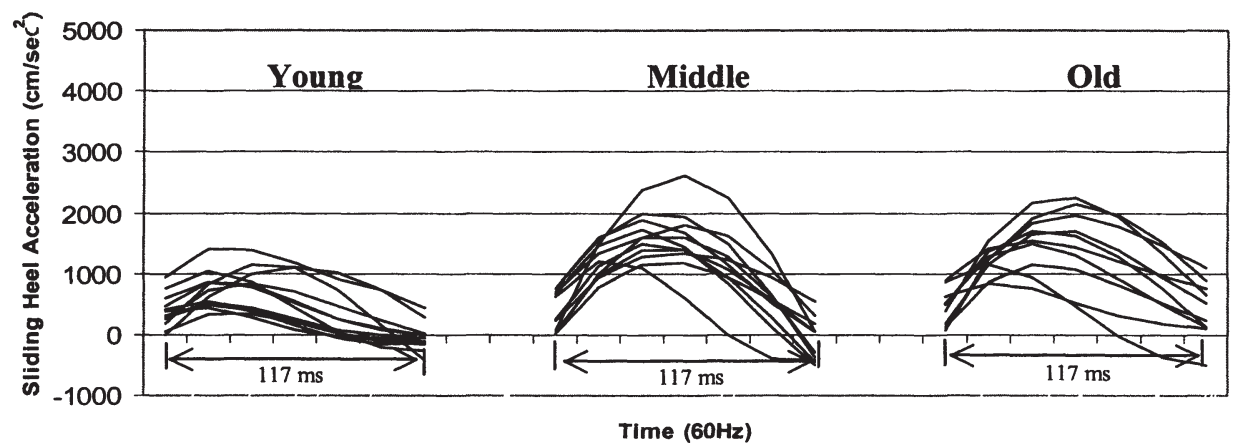

Figure 4. Composite patterns of sliding heel acceleration profiles starting from heel contact to 117 ms after heel contact on the oily vinyl floor surface among young, middle, and old subjects.

The results of a one-way ANOVA on average sliding heel acceleration $\left(H_{a c c}\right)$ indicated significant difference in this parameter as a function of age group $\left(F_{(2,39)}\right.$ $=5.448, p \approx 0.008)$. Tukey-Kramer post-hoc tests indicated that the older-age group's $H_{a c c}$ was significantly faster $(p \approx 0.0001)$ than younger age group. No statistically significant differences were found between the middle-age and older-age groups. (See Figure 4.)

The results of a one-way ANOVA on adjusted friction utilization (AFU) indicated significant difference in this parameter as a function of age group $\left(F_{(2,39)}=\right.$ $13.434, p \approx 0.0001)$. Tukey-Kramer post-hoc tests indicated that the older-age group's AFU was significantly higher $(p \approx 0.001)$ than younger-age group. No statistically significant differences were found between the middle-age and older-age groups.

The results of a one-way ANOVA analysis of RCOF indicated no statistically significant differences between the age groups $\left(F_{(2,39)}=2.392, p \approx 0.11\right)$. Figure 5 illustrates friction utilization (RCOF and AFU) as function of age groups.

The results of a two-way ANOVA on step length (SL) indicated a significant difference with respect to age group $\left(F_{(2,39)}=4.735, p \approx 0.0144\right)$. There were no statistically significant floor effects on SL $\left(F_{(2,39)}=3.166, p \approx 0.053\right)$. Tukey-Kramer post-hoc tests indicated that the middle age group's SL was significantly different $(p \approx 0.001)$ from younger and older subjects. The older subjects step length was significantly shorter than the younger subjects. (See Figure 6). 


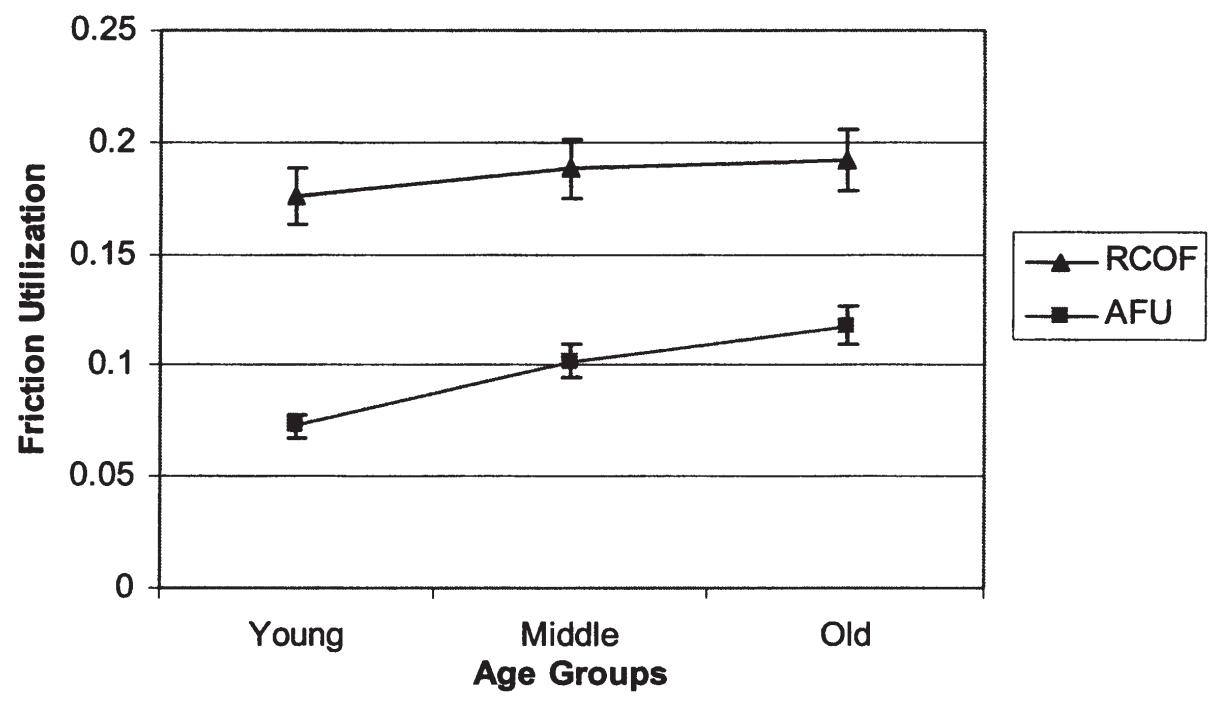

Figure 5. Friction utilization coefficients (RCOF and AFU) among three age groups. RCOF was obtained on the (not-slippery) carpeted floor surface and AFU was obtained on the (slippery) oily-vinyl floor surface.

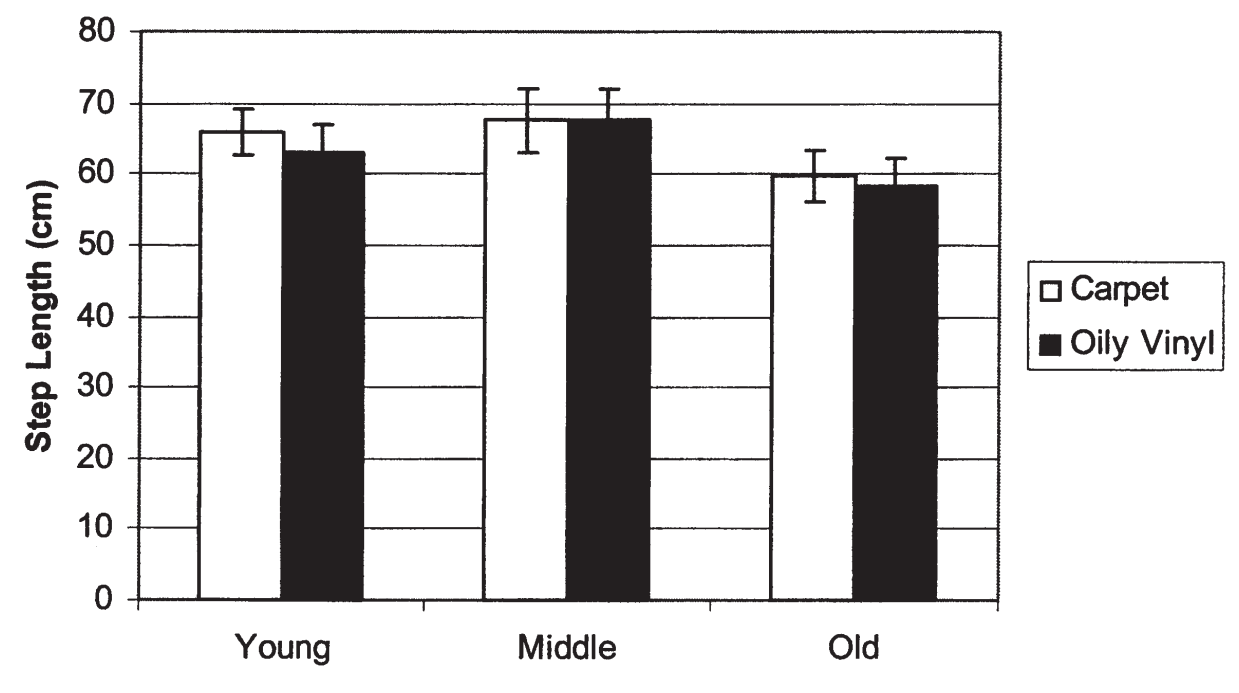

Age Groups

Figure 6. Step length of three age groups on the carpeted floor surface (not-slippery) and oily vinyl floor surface (slippery). Slippery floor surface was surreptitiously introduced to subjects. 


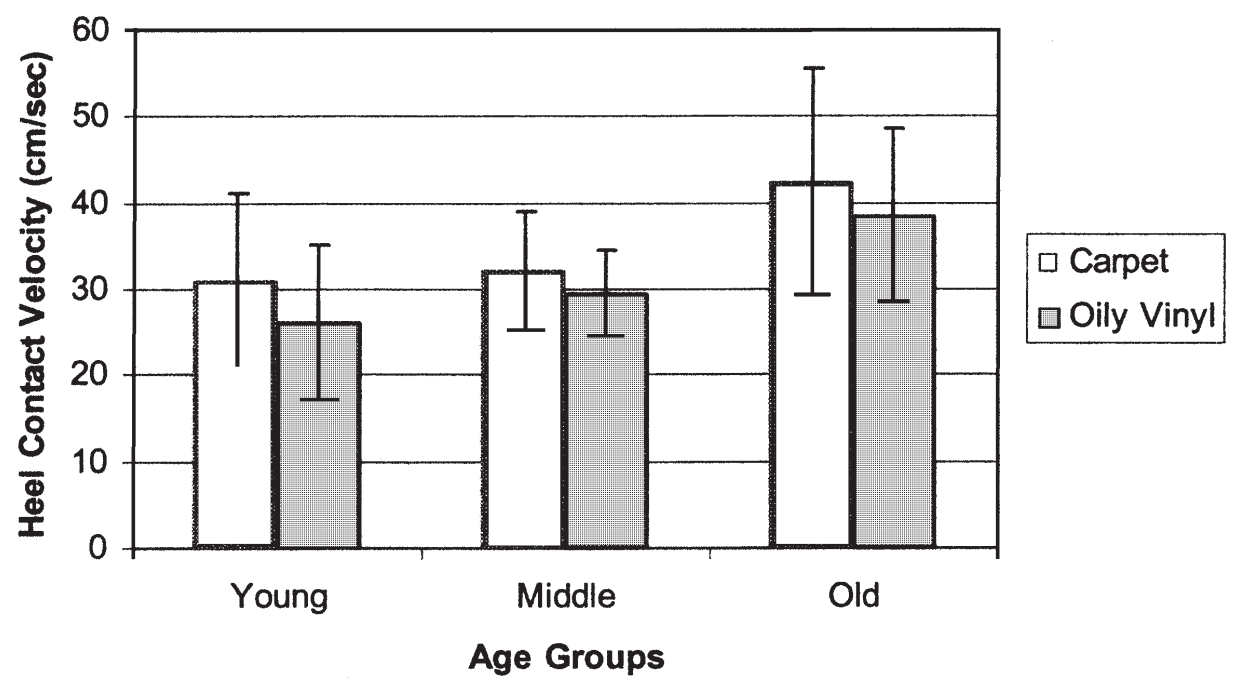

Figure 7. Heel contact velocity of three age groups on the carpeted floor surface (non- slippery) and oily vinyl floor surface (slippery). Slippery floor surface was inadvertently introduced to subjects. Heel contact was defined as the time when the vertical ground reaction force exceeded ION.

The results of a two-way ANOVA on heel contact velocity $\left(v_{h c}\right)$ indicated no statistically significant $(p>0.05)$ horizontal heel contact velocity $\left(v_{h c}\right)$ differences between the age groups $\left(F_{(2,39)}=20885, p \approx 0.0678\right)$. Additionally, there were no statistically significant $(p>0.05)$ floor effects on $v_{h c}\left(F_{(2,39)}=0.846, p \approx 0.437\right)$. (See Figure 7.)

\section{Fall Frequency}

A fall was identified if and only if two conditions were met:

1) when the sliding heel velocity was greater than the whole-body COM velocity (not reported here), and;

2) identifying a fall with visual inspection of the video recordings (i.e., subject's body clearly dropped towards the floor after slipping and was arrested by the harness before the impact).

The fall frequency results indicated that younger individuals in this study experienced 4 falls, middle-aged subjects experienced 8 falls, and older individuals experienced 12 falls. 
Table 3. Fall Recovery Threshold (FRT) across three age groups.

\begin{tabular}{lrrrc}
\hline Variables & Young & Middle & Old & $\mathrm{r}^{2 *}$ \\
\hline Initial Slip Distance I $(\mathrm{cm})$ & 3.90 & 3.80 & 3.12 & 0.92 \\
Sliding Heel Velocity $(\mathrm{cm} / \mathrm{s})$ & 144.45 & 145.26 & 107.63 & 0.86 \\
Sliding Heel Acceleration $\left(\mathrm{cm} / \mathrm{s}^{2}\right)$ & 1580.05 & 1310.52 & 1220.22 & 0.96 \\
\hline
\end{tabular}

* Coefficient of determination between each slip parameter and frequency of falls.

\section{Fall Recovery Threshold (FRT)}

To provide information regarding the relationship between slip parameters and fall accidents, a fall recovery threshold was developed utilizing slip parameters aggregated by age group, collected from runs where a fall occurred. Bivariate correlations between each slip parameter and the number of falls were calculated across each age group to determine the strength of the association between the parameters and falls. Results indicated that when the subjects in each age group exceeded the fall-recovery-threshold limits, a fall resulted. Additionally, a stronger association was found between the number of falls and sliding heel acceleration than with either slip distance or sliding heel velocity.

\section{Discussion}

Epidemiological findings suggest that older adults experience severe fall-related injuries more frequently than their younger counterparts [14,15]. Many possibilities for this difference have been proposed including both intrinsic (e.g., gait adaptation, musculoskeletal and sensory degradations) and extrinsic (e.g., medications and environments) factors, but with little agreement on actual mechanisms. It is not clear whether older adults experience severe fall-related injuries as a result of intrinsic factors associated with slip initiations (factors influencing friction demand such as gait adaptations) or due to uncompensated slips (factors influencing detection of and recovery from a slip). The aim of the current study was to provide better understanding of mechanisms involved in slip-and-fall accidents among different age groups.

Biomechanical analyses of human locomotion on slippery and non-slippery floor surfaces provided a method to assess slip severity among different age groups. We hypothesized that slip severity (as measured by slip distance, sliding heel velocity, sliding heel acceleration, and adjusted friction utilization) will be greater among older adults than their younger counterparts, resulting in more falls.

A method was developed to assess slip severity among different age groups. Utilizing three-dimensional coordinates of the heel and ground reaction forces, sliding motion of a foot on a slippery surface was characterized (i.e., distance, velocity, acceleration of the slipping foot, and friction demand). Specifically, slip distance was identified utilizing sliding heel velocity and acceleration profiles. Additionally, slip distance was further divided into $\mathrm{SD}_{\mathrm{I}}$ and $\mathrm{SD}_{\mathrm{II}}$. $\mathrm{SD}_{\mathrm{I}}$ was assessed to provide information concerning the severity of slip initiation, and $\mathrm{SD}_{\mathrm{II}}$ was assessed to provide information concerning the slip behavior after initiation of a slip. Furthermore, Peak Adjusted Friction Utilization (AFU) was calculated using ground reaction forces on the slippery floor surface to assess dynamic frictional requirements of the slipping foot. 
In order to assess if test subjects had any awareness that the floor surface had been switched from carpet to the oiled tile, step length and heel contact velocity were analyzed for both floor surfaces. Previous experiment indicated that heel contact velocity and step length were significantly reduced when knowingly walking on slippery floor surfaces [16]. Lack of significant differences for these variables with respect to the floor surface suggests that subjects in current study were not aware of the floorsurface changes.

As indicated by several researchers, initial gait characteristics such as longer step length and higher heel contact velocity may adversely increase friction demand (RCOF) at the shoe/floor interface, increasing the slip potential $[16,17,18]$. Consistent with previous findings $[16,18]$, older adults step length was shorter than their younger counterparts. Although older adults' heel-contact velocity was on the average higher than the younger adults, this was not statistically significant. Furthermore, older adults friction demand (RCOF) was not significantly higher than their younger counterparts. These findings suggest that slip potential for older adults are similar to younger adults, and that younger as well as older adults are equally prone to slip initiation. This statement is further supported by the $\mathrm{SD}_{\mathrm{I}}$ result on the slippery floor surface. No significant $\mathrm{SD}_{\mathrm{I}}$ differences among age groups suggest that shortly after the heel contact (approximately 60-80 ms), younger adults as well as older adults slipped.

Lockhart [19] writes that older individuals were susceptible to falls more often than their younger counterparts. Consistent with previous findings, older adults experienced more falls than did the younger adults. Older adults slipped longer $\left(\mathrm{SD}_{\mathrm{II}}\right)$ and faster than the younger age group. Furthermore, the middle-aged group exhibited slipping characteristics much like their older counterparts. Fall Recovery Threshold (FRT) measures suggest that sliding heel acceleration during slipping was a stronger fall predictor than sliding heel velocity. Furthermore, younger individuals FRT was higher on the average and suggests that the fall recovery threshold is not all same for the different age groups (i.e., younger subjects can slip longer and faster than older subjects and still recover from a slip - preventing a fall). Thus, in a given situation, older adults are at a higher risk for fall accidents. This result is further supported by higher AFU values for the older individuals. As indicated, younger individuals AFU (.074) was adjusted within the dynamic friction requirements (0.08). However, on the average, middle-aged $(\mathrm{AFU}=0.10)$ and older individuals $(\mathrm{AFU}=0.12)$ could not. Consequently, the result was longer slip distance $\left(\mathrm{SD}_{\mathrm{II}}\right)$ and increased frequency of falls. Lockhart [19] wrote that the ability to successfully recover from a slip (thus preventing a fall) was affected by lower-extremity muscle strength, and sensory degradation among older adults. Thus, it seems that slip severity is dependent upon intrinsic changes associated with aging. Although implicated, further study investigating mechanisms involved in higher sliding speeds and slip compensation are needed.

\section{Conclusions}

1) All subjects slipped when confronted with the oily vinyl tile.

2) Older adults' friction demand (RCOF) and initial slip distance $\left(\mathrm{SD}_{\mathrm{I}}\right)$ were not significantly different from their younger counterparts.

3) Older adults' slip potential at the time of the heel contact to shortly after the heel contact (i.e., slip initiation) are similar to the slip potential of younger adults, and that younger as well as older adults are prone to the slip initiation. In other words, 
the characteristics of the slip initiation were very similar among the different age groups.

4) Differences of import occurred after slip initiation. Older adults slipped longer (greater $\mathrm{SD}_{\mathrm{II}}$ ) and faster than younger adults.

5) Fall-recovery-threshold (FRT) parameters indicated that younger adults were better able to recover from a slip (thus preventing a fall) with much higher sliding speed and longer slip distance suggesting that recovery thresholds (in terms of slip distance and sliding speeds) are not-at-all the same for the different age groups.

6) Older adults' were unable to lower their friction utilization on the slippery floor. If the utilized friction cannot be brought within the dynamic friction requirements, a fall is likely to occur.

7) We hypothesize that the inability to control slipping responses may be a result of the sensory degradation and muscle weakness.

8) Most of the current research on slips and falls concentrates predominantly on initiation of slips (i.e., RCOF), however, this study indicates that how slips result in a fall is important as well, especially for older adults.

9) Future research should focus not only upon the dynamics of slips, but upon the dynamics of falls.

10) It might be useful to explore shoe-bottom materials that have an increasing friction/velocity characteristic.

\section{Acknowledgments}

This research was supported by the National Institute of Health (NIOSH) grant R03/small grant. The paper's contents are solely the responsibility of the authors and do not necessarily represent the official views of the NIH.

The authors would like to thank Mark Marpet for his valuable comments and stimulating discussions.

\section{References}

[1] National Safety Council, Accidents Facts 1998 edition. Itasca, IL.: NSC.

[2] Englander, F., Hodson, T. J., Terregrossa, R. A., “Economic Dimensions of Slip and Fall Injuries," Journal of Forensic Sciences, 41(5): 733-746.

[3] Andersson, R. and Lagerlof, E., "Accident Data in the New Swedish Information System on Occupational Injuries," Ergonomics, Vol. 26, 1983, pp. 33-42.

[4] Courteney, T. K., Sorock, G. S., Manning, D. P., Collins, J. W., and Holbein-Jenny, M. A., "Occupational Slip, Trip, and Fall-Related Injuries - Can the Contribution of Slipperiness be Isolated?" Ergonomics, Vol. 44, No. 13, 2001, pp. 1118-1137.

[5] Miller, J., "Slippery Work Surfaces: Towards a Performance Definition and Quantitative COF Criteria," J. of Safety Research, Vol. 14, 1983, pp. 145-158.

[6] Leamon, T. B. and Son, D. H., 1989, "The Natural History of a Microslip," Advances in Industrial Ergonomics and Safety I. Taylor \& Francis, 633-638. 
[7] Gronqvist, R., Abeysekera, J., Gard, G., Hsiang, S. M., Leamon, T. B., Newman, D. J., Gielo-Perczak, K., Lockhart, T. E., and Pai, C., “Human-centred approaches in slipperiness measurement," Ergonomics, Vol. 44, No. 13, pp. 1167-1199.

[8] Perkins, P. J., "Measurement of Slip Between the Shoe and Ground During Walking," American Society of Testing and Materials, Special Technical publication 649, 1978, pp. 71-87.

[9] Perkins, P. J., and Wilson, M. P., "Slip Resistance Testing of Shoes-New Developments," Ergonomics, Vol. 26, No. 1, 1983, pp. 73-82.

[10] Strandberg, L. and Lanshammar, H., "Walking Slipperiness Compared to Data From Friction Meters," in Winter, D. A., Norman, R. W., Wells, R. P., Hayes, K. C., and Patia, A. E., (eds.), Biomechanics IX-B, Champaign, IL: Human Kinetics Publishers, 1985, pp. 76-81.

[11] Strandberg, L. and Lanshammar, H., "The Dynamics of Slipping Accidents," Journal of Occupational Accidents, Vol. 3, 1981, pp. 153-162.

[12] MacKinnon, C. D. and Winter, D. A., "Control of Whole Body Balance and Posture in the Frontal Plane During Human Walking," J. Biomechanics, Vol. 26, No. 6, 1993, pp. 633-644.

[13] Son, D. H., “The Effect of Postural Changes on Slip and Fall Accidents," Ph.D. Dissertation, Texas Tech University, 1990.

[14] Agnew, J. and Suruda, A. J., 1993, Age and fatal work-related falls. Human Factors, 35(4), 731-736.

[15] Rubestein, L. Z., Robbins, A. S., Schulman, B. L., Rosado, J., Osterweil, D., \& Josephson, K. R., 1988, Falls and instability in the elderly. J. Am. Geriatrics Society, 36, 266-278.

[16] Lockhart, T. E., 1997, The ability of elderly people to traverse slippery walking surfaces. Proceedings of the Human Factors and Ergonomics Society 41st Annual Meeting, 1: 125-129.

[17] Redfern, M. S., Cham, R., Gielo-Perczak, K., Gronqvist, R., Hirvonen, M., Lanshammar, H., Marpet, M., Pai, C. Y., Powers, C., 2001, Biomechanics of slips. Ergonomics, Vol. 44, No. 13, 1138-1166.

[18] Winter, D. A., Patia, A. E., Frank, J. S., and Walt, S. E., 1990, Biomechanical walking pattern changes in the fit and healthy elderly. Phys. Ther. 70: 340-347.

[19] Lockhart, T. E., Smith, J. L., Woldstad, J. C., and Lee, P. S., “Effects of Musculoskeletal and Sensory Degradation due to Aging on the Biomechanics of Slips and Falls," Proceedings of the IEA/HFES Conference, Vol. 5, 2000, pp. 83- 86. 